\title{
Comparison study among the different existing loss of excitation protection schemes in synchronous generator
}

\author{
Ayache MATI(1),Hamid BENTARZI(1) ${ }^{*}$, Jean-Claude MAUN(2) \\ (1) Laboratory Signals and Systems (LSS), IGEE, University M'hamed Bougara Boumerdes, Algeria \\ (2) Beams, ULB, Brusselles, Belgium \\ ${ }^{*}$ Corresponding author e-mail: h.bentarzi@univ-boumerdes.dz
}

\begin{abstract}
Synchronous generator is the most important element of a power system and its fast and reliable protection is crucial. One of the most abnormal conditions in a generator is loss of excitation (LOE) which is harmful to both the generator and the power system. This condition should be detected and the generator isolated from the system to avoid generator damage as well as power system instability.

This work presents an experimental study and comparison of the two conventional LOE protection schemes, negative-offset and positive-offset mho element under different conditions. The results show that the two schemes can detect LOE fault under total or partial LOE conditions, however in terms of speed (fault detection time) the positive offset scheme is faster than the negative offset scheme under all loading conditions. Besides, the two LOE protection schemes are reliable and do not operate under power swing disturbances caused by any type of external faults.
\end{abstract}

Keywords: Loss Of Excitation (LOE), positive-offset mho element, negative-offset mho element, loading conditions.

\section{INTRODUCTION}

The earliest Loss Of Excitation (LOE) protection scheme employs an over-current and under-voltage relays based on the measurement of machine field current. However, this scheme may not operate during all system conditions [1]. An approach for LOE detection based on a single-phase negative-offset mho element is introduced first by Mason [2]. A later approach contains two characteristic zones introduced by Berdy [3], designed to improve the relay robustness during transient swings and low frequency disturbances. This approach has been improved by combining a positive-offset element and a directional unit, which provides security for close in external faults [4]. There are also some other types of LOE protection schemes, such as G-B scheme, P$Q$ scheme and $U-I$ scheme, but they are not widely used [5] [6].

To enhance the performance of LOE detection algorithm, in term of speed (fault detection time), reliability, security and selectivity, especially to discriminate the LOE event from power swings, some other techniques have been proposed:

- Free settings approach based on the rate of change of resistance [5],
- Dynamic simulations introduced by Ref. [7] aiming to improve the generator LOE protection.

- LOE detection algorithm based on a digital-phase comparator [8],

- In order to coordinate between LOE protection and generator underexcitation controls considering power system dynamics, a real time digital simulator (RTDS) framework is introduced in [9],

- Artificial neural network based fault classification algorithms [10]

- Support vector machine (SVM)based technique for identifying lossof excitation condition from powerswing disturbances [11],

- Protection by using the rate of change of reactance [12]

- LOE relay based on fuzzy interface mechanisms [13],

- Adaptive loss of field protection using an approach for on-line identifying system equivalent impedance based on PMU measurements [14],

- Combined scheme based on the derivative of the terminal voltage and the output reactive power of the generator [15], 
- Combined criteria using voltage magnitude, voltage angle, and reactive power [16],

- LOE detection based on decision tree technique [17],

- Analytical technique based on the generator armature current variation [18],

- New approach for LOE faults detection in hydro-generators using adaptive neuro fuzzy inference system is presented in [19],

- Analytical approach based on internal voltage calculation [20],

- New approach for dependable and secure LOE detection relay based on rotor signals estimation [21],

- Secure and setting-free technique based on different electrical quantities of the generator [22],

This work presents a comparative study of the two conventional LOE protection schemes, negative-offset and positive-offset mho elements under different conditions. In terms of speed, the two schemes are compared under total and partial loss of excitation. Then, in terms of security against power swings, the two schemes are compared under different external faults.

\section{GENERATOR LOSS OF EXCITATIONCAUSES}

When a generator loses excitation, the magnetic coupling between rotor and stator magnetic fields gradually decreases until the machine loses synchronization. Besides, the generator will overspeed and operate as an induction generator obtaining its excitation from the system by absorbing reactive power [7]. Therefore, the generator may be completely or partially loss its excitation through such incidents as:

- Field breaker accidental tripping,

- Field open circuit,

- Field short circuit (flashover of the slip rings),

- Voltage regulation system failure.

- Loss of supply to the excitation system.

Furthermore, when a generator loses excitation, both the machine and the power system are at risk. The generator may suffer rotor over-heating, stator winding overload, stator end-core damage and mechanical failure. The power system may have voltage collapse, unnecessary relays tripping and loss of synchronism of some normal operating generators [4] [23].

The disturbance severity during generator loss of excitation depends primarily on the generator initial loading as clearly shown in Fig.3.1. Curve (a) shows the impedance trajectory with initial full load at point $C$ and terminates at point $D$ above the average of the direct and quadrature-axis sub-transient generator impedances ( $X \mathrm{~d}$, $X q)$. Curve (b) shows a generator that initially operates at 30 percent load and underexcited. In this case, the impedance trajectory follows the path from $E$ to $F$ to $G$ and oscillates in the region between $\mathrm{F}$ and $\mathrm{G}$. Usually, under any generator loading the impedance trajectory will end at the area inside the dashed curve from $D$ to L. [4]

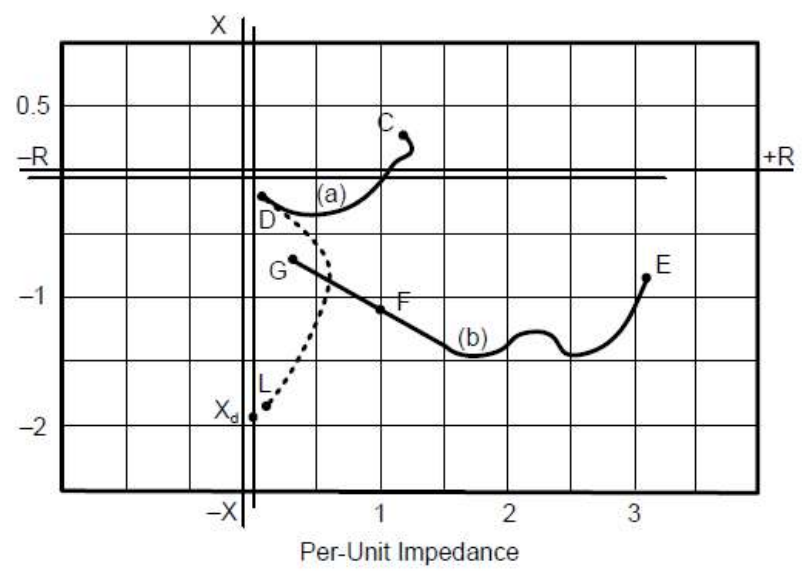

Fig.1. Generator loss-of-excitation characteristic[4].

Moreover, the induction generator slip depends on the generator initial load; the higher initial load produces a higher slip value and a lower generator impedance, which means higher reactive-power consumption, higher stator and rotor currents, and lower terminal voltage. Hence, the worst case is when the generator loses excitation at full load, where slip is typically in the 2 to $5 \%$ range [7].

\section{IMPEDANCE-BASED LOSS OF EXCITATION PROTECTION SCHEMES}

There exist two basics LOE protection schemes, negative-offset and positive-offset mho elements [4]. The two schemes based on impedance calculation at the generator terminals, using the measured currents and voltages as shown in Fig.2. 


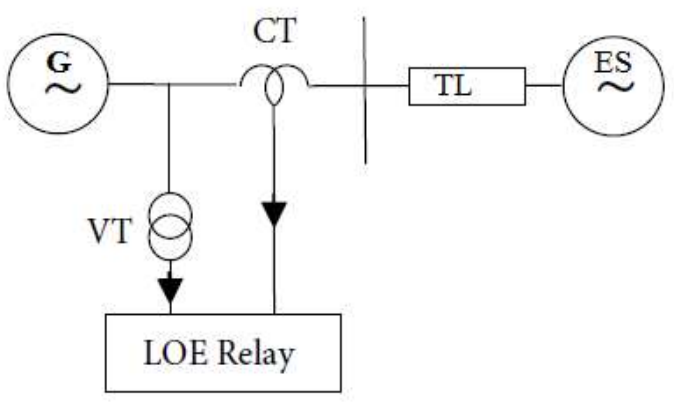

Fig. 2 Generator loss-of-excitation protection.

In order to construct the R-X diagrams for a balanced three phase conditions, the $R$ and $X$ should be determined as follow:

$$
\begin{aligned}
& R=\frac{P \times V^{2}}{P^{2}+Q^{2}} \\
& \quad X=\frac{Q \times V^{2}}{P^{2}+Q^{2}}
\end{aligned}
$$

in which, $P, Q$ and $V$ are the active power, the reactive power and the voltage of the relay location, respectively.

\section{Negative-offset mho element}

This protection scheme uses two zones mho impedance-based units as shown in Fig.3. Both zones have the same offset that is equal to half of the direct-axis transient reactance [24]:

$$
\text { Offset }=\frac{X_{d}^{\prime}}{2}
$$

The first zone $(\mathrm{Z1})$ is set with a diameter equal to $1.0 \mathrm{pu}$ (generator base); this element detects LOE during high loading conditions down to about $30 \%$ load. A short time delay of $0.1 \mathrm{~s}$ is allowed to prevent misoperations during switching transients.

The second zone $(Z 2)$ is set with a diameter equal to the direct axis synchronous reactance $(\mathrm{Xd})$. This element detects $\mathrm{LOE}$ during light loading conditions. A time delay of 0.5 to $0.6 \mathrm{~s}$ is allowed to prevent misoperations during power swings.

\section{Positive-offset mho element}

This protection scheme uses a combination of two mho impedance-based units and a directional unit as shown in Fig.4. The first Zone (Z1) has a negative offset mho characteristic, and it is set using the following equations [24]:

$$
\text { Diameter }=1.1 X_{d}-\frac{X_{d}^{\prime}}{2}
$$

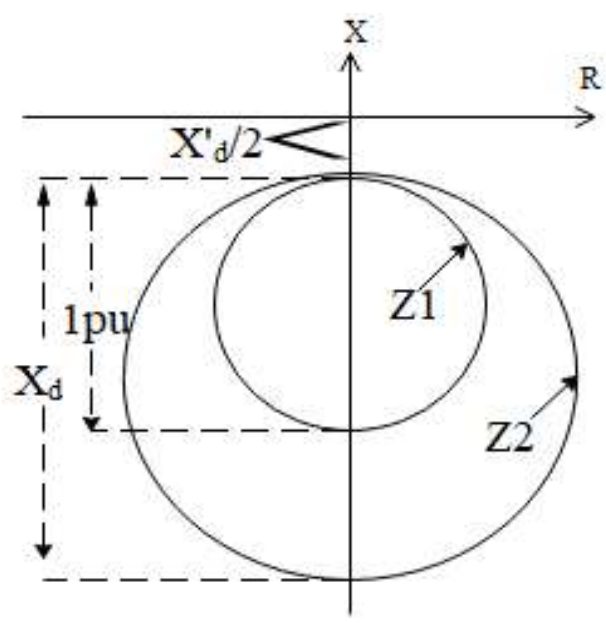

Fig.3. Negative-offset mho element, LOE protection scheme.

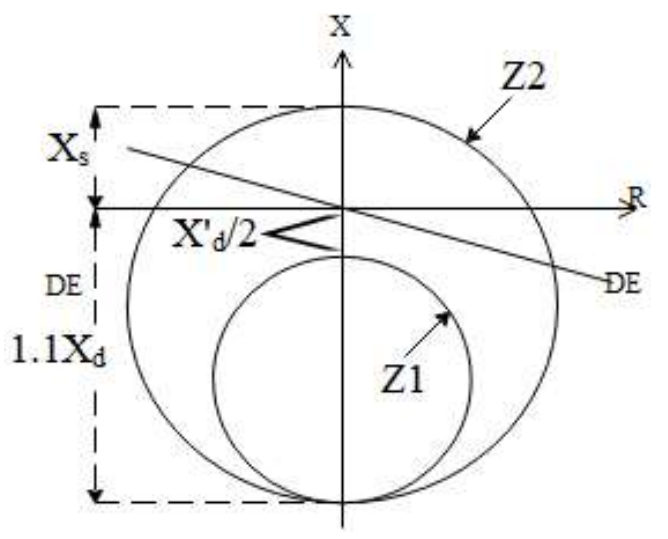

Fig.4. Positive-offset mho element, LOE protection scheme.

$$
\text { Offset }=\frac{X_{d}^{\prime}}{2}
$$

A time delay of 0.1 to 0.3 second is recommended to prevent male-operation under transient swings.

The second zone (Z2) has a positive-offset mho characteristic, and it is set using the following equations:

$$
\begin{gathered}
\text { Diameter }=1.1 X_{d}+X_{s} \\
\text { Offset }=X_{s}
\end{gathered}
$$

Where XS is the sum of all the impedances away from the generator terminals (up to relay location) in per unit. A time delay may be considered between 0.25 to 1 second [24].

Moreover, this positive offset element is controlled by a directional element to prevent mal-operation when close external 
faults occur. The directional element is set at an angle between 10 and 20 degrees. Therefore, a failure on the minimum excitation limiter might occur. Hence, both the directional and the mho element operate and initiate an alarm. A one minute time delay may be introduced in many cases to trip the unit if the situation cannot be restored before the damage proposed [4] [10].

\section{EXPERIMENTAL STUDY}

\section{Experimental setup}

In this experimental study, a real single machine infinite bus (SMIB) is used. The model as shown in Fig.5, consists of a 10 KVA synchronous generator, connected via $110 / 440 \mathrm{v}$ step-up transformer to a large system (Belgium Grid) through a transmission line. Fig. 6 presents the block diagram of the

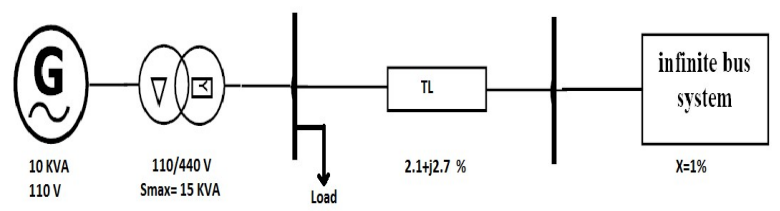

experimental setup that has been done at the BEAMS Laboratory, ULB, Brussels. The system data are given in appendix $A$.

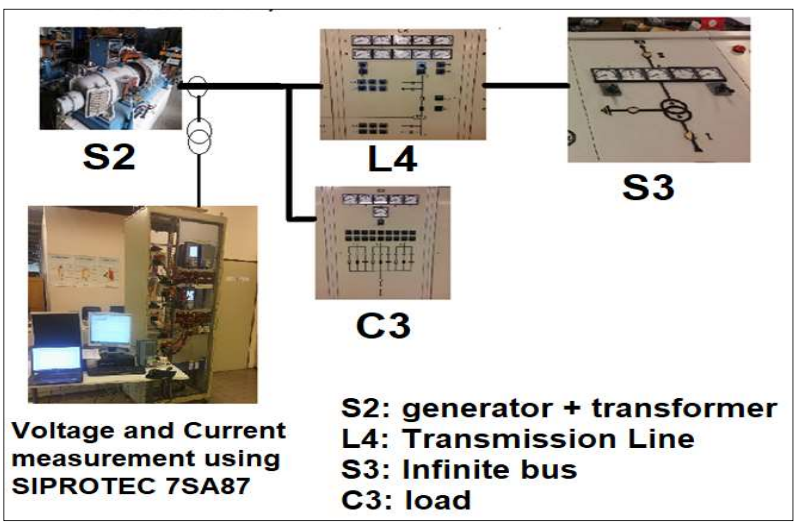

Fig. 5 Experimental power system model.

Fig. 6 Block diagram of the experimental setup.

LOE protection schemes settings:

Negative-offset mho element setting:

Zone 1: Circle diameter: 1 pu.

Offset $=0.06 \mathrm{pu}$

Time delay: $0.1 \mathrm{~s}$

Zone 2: Circle diameter $=1.13 \mathrm{pu}$.

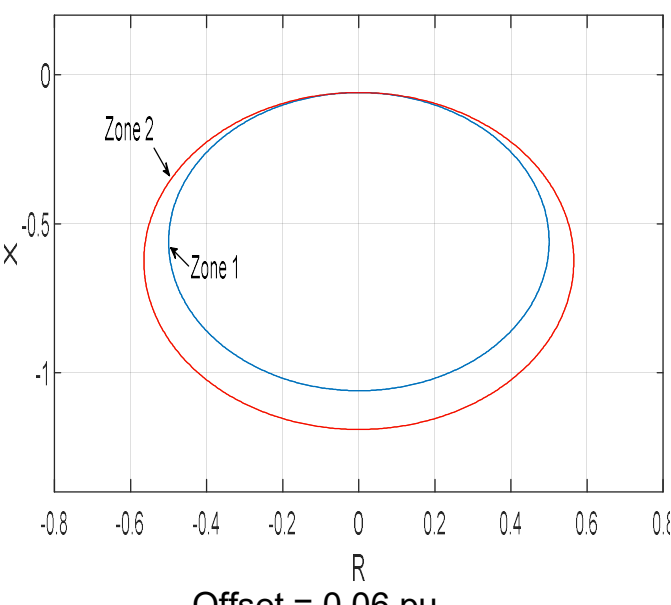

Offset $=0.06 \mathrm{pu}$

Time delay: $0.6 \mathrm{~s}$

Fig. 7 Negative-offset mho element settings.

Positive-offset mho element setting:

Zone 1: Circle diameter $1.095 \mathrm{pu}$.

Offset $=0.06 \mathrm{pu}$

Time delay: $0.1 \mathrm{~s}$

Zone 2: $\quad$ Circle diameter $=1.443 \mathrm{pu}$.

Offset $=0.2$

Time delay: $1 \mathrm{~s}$

Directional element: set with angle $-18^{\circ}$

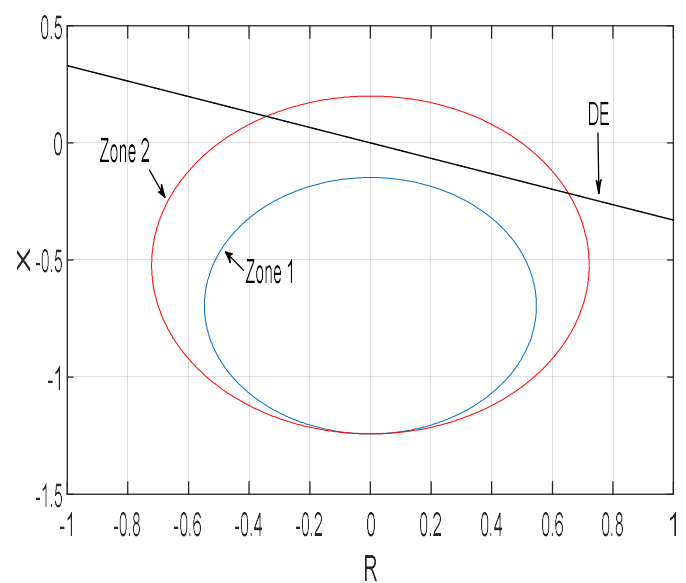

Fig. 8 Positive-offset mho element settings.

\section{Experimental Results}

Experimental tests have been done under different conditions; total LOE, partial LOE and under external faults. Simulation studies in order to analyze the constructed data from the numerical relay (SIPROTEC 7SA87) have been conducted using 
Simulink/MATLAB software, where the two conventional LOE protection schemes, negative-offset and positive-offset mho elements are compared.

\section{a) Experimental comparison under TLOE}

Total (complete) loss of excitation is considered on the generator after $19 \mathrm{~s}$ of starting the recording time with $100 \%$ initial load. Fig. 9 shows the generator real and reactive power transient time responses during LOE with $100 \%$ initial load. It can be seen from this figure that due to the LOE at around $20 \mathrm{~s}$, the generator real power decreased sharply before loss of synchronism. Moreover, the reactive power

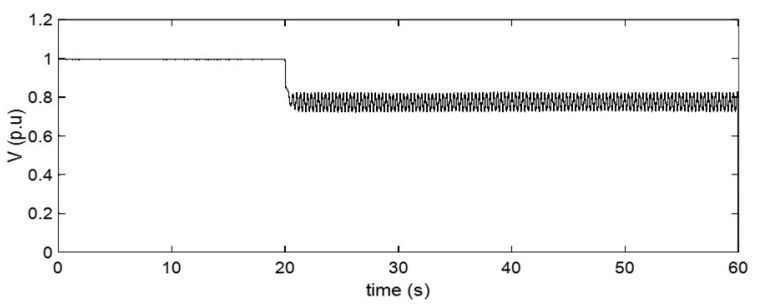

output decreases sharply to negative singe, which means that the generator starts to absorb the reactive power from the system until it losses the synchronism.

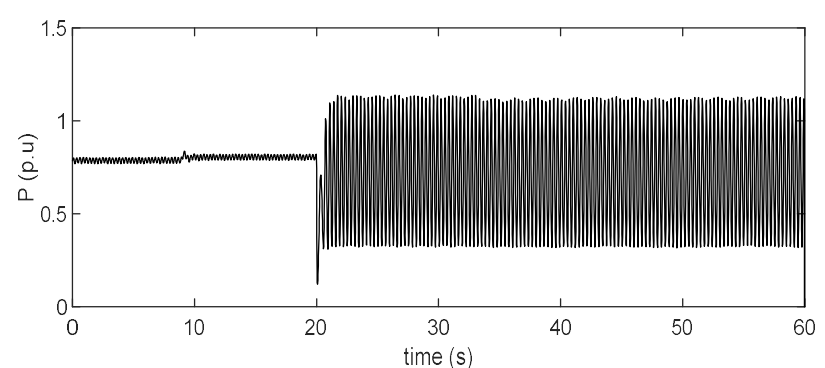

Fig. 9 Generator active and reactive power during

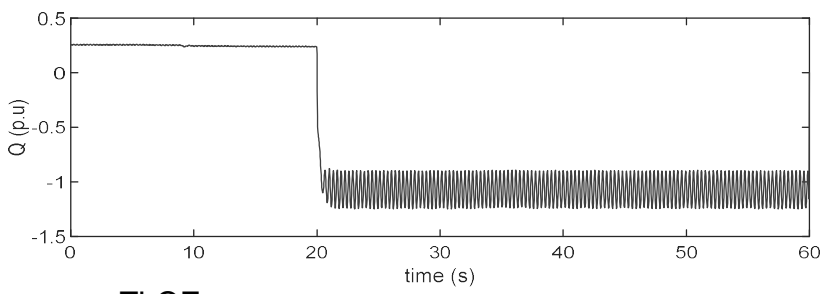

TLOE.

Fig. 10 Generator terminal voltage during TLOE.

Figure 10 shows the generator terminal voltage before and after TLOE. Therefore, due to the large amount of the absorbed reactive power after the $\mathrm{LOE}$, the phase current increased sharply before loss of synchronism. However, the terminal voltage

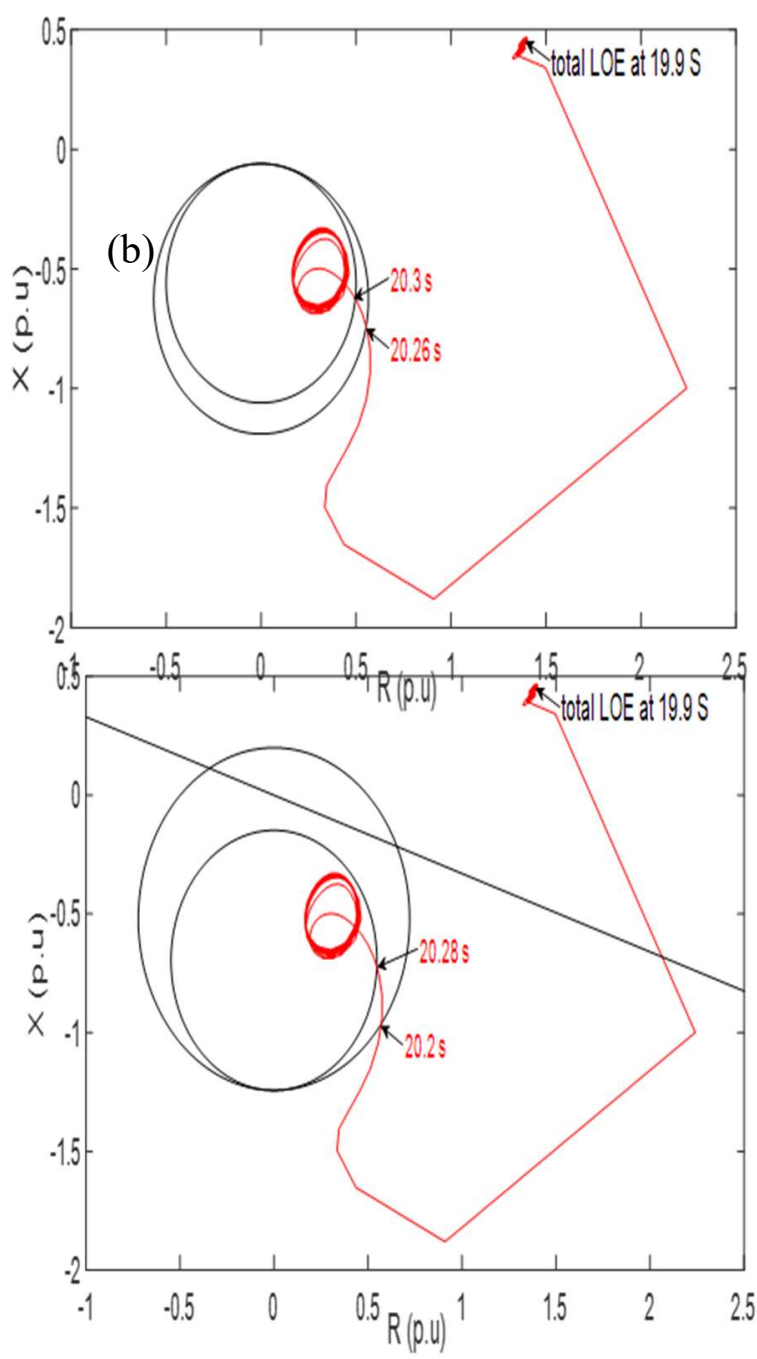

Fig. 11 Impedance trajectory measured by: a) positive-offset mho element. b) negative-offset mho element.

decreases until it reaches almost 0.8 p.u. and starts to oscillate.

Figure 11 depicts the impedance trajectories measured by the two different LOE protection schemes. The impedance trajectory starts at $19.9 \mathrm{~s}$ after

(a) TLOE occurred, and penetrates zone 2 of the positive-offset mho element (Fig. 11a) at 20.2 $\mathrm{s}$, then penetrates zone 1 at $20.28 \mathrm{~s}$. this protection scheme trips by zone 1 (after its timer of $0.1 \mathrm{~s}$ is timed out) at $\mathrm{t}=20.38 \mathrm{~s}$, this means that the clearing time is $t=0.48 \mathrm{~s}$. However, the impedance trajectory penetrates zone 2 of the negative-offset mho element (Fig. $11 \mathrm{~b}$ ) at $20.26 \mathrm{~s}$, then penetrates zone 1 at $20.3 \mathrm{~s}$ this protection scheme trips by zone 1 (after its timer of $0.1 \mathrm{~s}$ is timed out) at $\mathrm{t}=20.4 \mathrm{~s}$, the clearing time is $\mathrm{t}=0.5 \mathrm{~s}$.

Comparing the two clearing times shows that, the clearing time of the positive-offset mho element is less than the clearing time of the 
negative-offset mho element by $0.02 \mathrm{~s}$ under

\begin{tabular}{|c|c|c|c|c|c|}
\hline & \multicolumn{4}{|c|}{ Initial load $S=P+j Q \quad(p u)$} \\
\hline & & $100 \%$ & $60 \%$ & $40 \%$ & $10 \%$ \\
\hline \multirow{6}{*}{$\begin{array}{l}\text { Clearing } \\
\text { time (s) }\end{array}$} & Positive- & 0.48 & 0.5 & 0.64 & 1.6 \\
\hline & OIISel & Zone1 & Zone1 & Zone1 & Zone1 \\
\hline & element & & & & \\
\hline & Negative- & 0.5 & 0.52 & 0.68 & 1.84 \\
\hline & $\begin{array}{l}\text { Offset } \\
\text { mho }\end{array}$ & Zone1 & Zone1 & Zone1 & Zone2 \\
\hline & element & & & & \\
\hline
\end{tabular}

the same initial load.

The same experimental study under different initial loading have been repeated and presented in Table 1 . The results show that when a total loss of excitation occur, the positive-offset mho element protection scheme is faster than the negative-offset mho element under all loading conditions.

Table 1 Clearing time of the two LOE protection schemes under TLOE

\section{b) Experimental comparison under PLOE}

Comparison studies of the two LOE protection schemes under different initial loading and with two different partial loss of excitation conditions ( $\mathrm{Ef}=0.4 \mathrm{pu} / \mathrm{Ef}=0.2$ pu) are presented in Tables 2 and 3 . The results show that when a partial loss of

\begin{tabular}{|c|c|c|c|c|c|}
\hline \multirow{2}{*}{\multicolumn{2}{|c|}{$E f=0.2 p u$}} & \multicolumn{4}{|c|}{$\begin{array}{l}\text { Initial load } S=P+j Q \\
(\mathrm{pu})\end{array}$} \\
\hline & & $\begin{array}{l}100 \\
\%\end{array}$ & $60 \%$ & $\begin{array}{l}40 \\
\%\end{array}$ & $\begin{array}{l}10 \\
\%\end{array}$ \\
\hline \multirow{2}{*}{$\begin{array}{l}\text { Clearin } \\
g \text { time } \\
\text { (s) }\end{array}$} & $\begin{array}{l}\text { Positive- } \\
\text { offset } \\
\text { mho } \\
\text { element }\end{array}$ & $\begin{array}{l}1.98 \\
\text { Zone } \\
1\end{array}$ & $\begin{array}{l}3.48 \\
\text { Zon } \\
\text { e } 1\end{array}$ & UR & UR \\
\hline & $\begin{array}{l}\text { Negative } \\
\text {-offset } \\
\text { mho } \\
\text { element }\end{array}$ & $\begin{array}{l}2.02 \\
\text { Zone } \\
1\end{array}$ & $\begin{array}{l}3.76 \\
\text { Zon } \\
\text { e } 1\end{array}$ & UR & UR \\
\hline
\end{tabular}

excitation occur, the fault clearing time of the positive-offset mho element protection scheme is faster than the negative-offset mho element protection scheme. However, when a partial loss of excitation occur under light loading, the fault will not cleared (under reach).
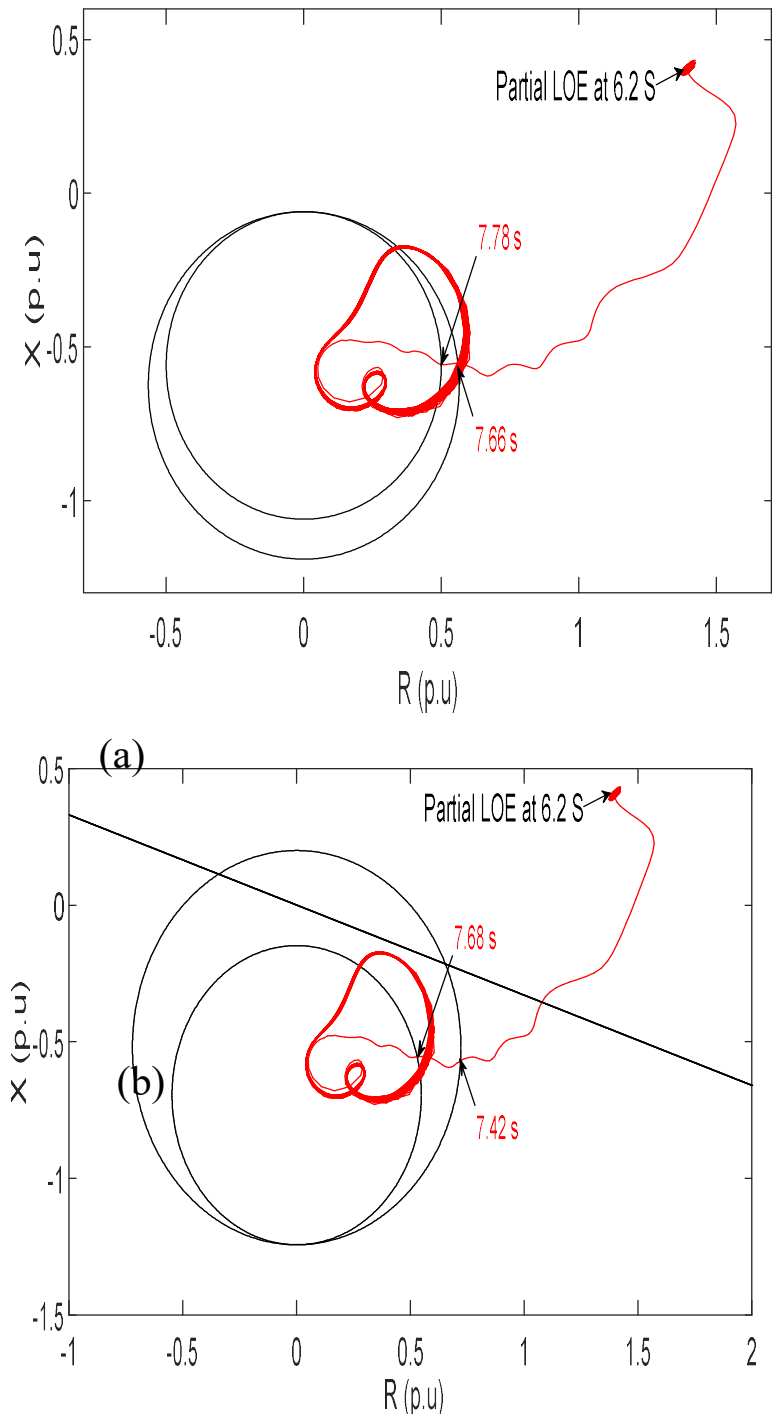

Partial loss of excitation $(E f=0.4$ $\mathrm{pu}$ ) is considered on the generator after $6.2 \mathrm{~s}$ of starting the recording time.

Figure 12 depicts the impedance trajectories measured by two different LOE protection schemes under PLOE.

the

schemes under PLOE.

UR: under reach

Fig. 12 Impedance trajectory measured by: a) positive-offset mho element. b) negative-offset mho element. Under PLOE.

Table 3 Clearing time of the two LOE protection schemes under PLOE. 

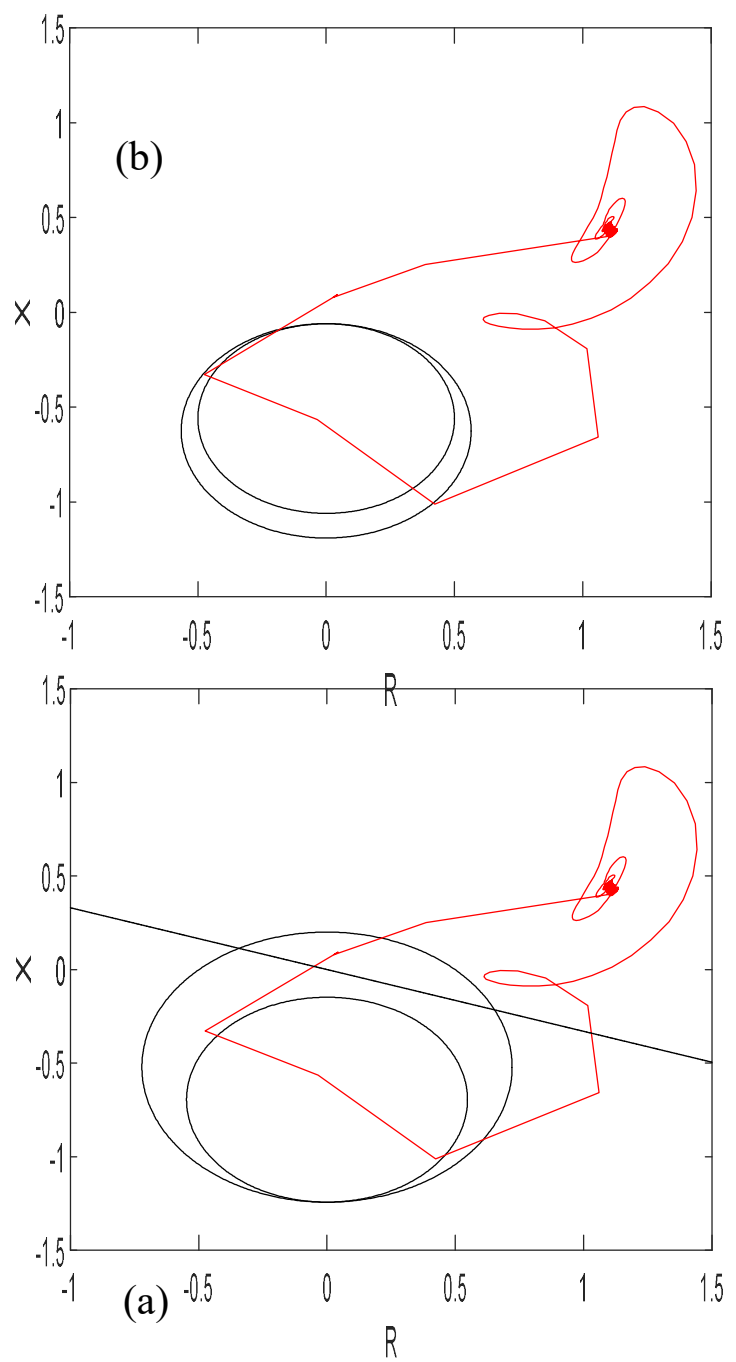

Fig.13 Impedance trajectory under threephase external fault measured by: a) positiveoffset mho element. b) negative-offset mho element.

\begin{tabular}{|l|l|l|l|l|l|}
\cline { 3 - 6 } \multicolumn{2}{c|}{} & \multicolumn{3}{|l}{$\begin{array}{l}\text { Initial load S } \\
\text { (pu) }\end{array}$} \\
\cline { 3 - 6 } & $100 \%$ & $60 \%$ & $40 \%$ & $10 \%$ \\
\hline \multirow{2}{*}{$\begin{array}{l}\text { Clearing } \\
\text { time (s) }\end{array}$} & $\begin{array}{l}\text { Positive- } \\
\text { offset } \\
\text { mho } \\
\text { element }\end{array}$ & NO & NO & NO & NO \\
\cline { 2 - 6 } & $\begin{array}{l}\text { Negative- } \\
\text { offset } \\
\text { mho } \\
\text { element }\end{array}$ & NO & NO & NO & NO \\
\hline
\end{tabular}

\section{c) Experimental comparison under external faults}

In order to investigate the behavior of the tow LOE protection schemes in external fault situation, a three-phase fault is applied
(200 ms fault duration), with 100\% initial load; Fig. 13 depicts the impedance trajectories measured by the two different LOE protection schemes. The impedance trajectory penetrates the two zones of the tow schemes. Because the maximum duration time does not exceeds the time delay of the two zones, the two protection schemes will not operate.

The same simulation study under different initial loading and with two different fault durations have been repeated, the results are presented in Table 3.The results show that the two LOE protection schemes will not operate under power swings disturbances caused by any type of external fault for 200 ms fault duration.

Table 4 The effect of three phase to ground external fault on LOE protection schemes.

\begin{tabular}{|c|c|c|c|c|c|}
\hline \multirow{2}{*}{\multicolumn{2}{|c|}{$E f=0.4 p u$}} & \multicolumn{4}{|c|}{$\begin{array}{l}\text { Initial load } S=P+j Q \\
\text { (pu) }\end{array}$} \\
\hline & & $100 \%$ & $\begin{array}{l}60 \\
\%\end{array}$ & $\begin{array}{l}40 \\
\%\end{array}$ & $\begin{array}{l}10 \\
\%\end{array}$ \\
\hline \multirow{2}{*}{$\begin{array}{l}\text { Clearin } \\
g \text { time } \\
\text { (s) }\end{array}$} & $\begin{array}{l}\text { Positive- } \\
\text { offset } \\
\text { mho } \\
\text { element }\end{array}$ & $\begin{array}{l}1.58 \\
\text { Zone } \\
1\end{array}$ & UR & UR & UR \\
\hline & $\begin{array}{l}\text { Negative } \\
\text {-offset } \\
\text { mho } \\
\text { element }\end{array}$ & $\begin{array}{l}1.68 \\
\text { Zone } \\
1\end{array}$ & UR & UR & UR \\
\hline
\end{tabular}

NO: No Operation

\section{CONCLUSION}

This work presents the study on one of the most abnormal condition in synchronous generator, which is the loss of excitation (LOE). Experimental studies have been conducted using the single machine infinite bus (SMIB) and the two conventional LOE protection schemes, negative-offset and positive-offset mho elements are modeled.

Consequently, a comparative experimental study of the two traditional LOE protection schemes is investigated. The obtained results show that the two LOE protection schemes detects the fault under total or partial LOE; however, in terms of speed the positive-offset mho element is faster than the negative-offset mho element. Furthermore, the two LOE protection schemes are reliable and will not operate under power swing disturbances caused by any type of external faults. Therefore, the positive-offset mho element protection scheme has been selected 
because it gives the best performance in terms of speed (fault detection time).

\section{Appendix A}

Parameters of the experimental setup elements in BEAMS Lab, University ULB,Brusselles, Belgium.

1) Generator parameters: $10 \mathrm{KVA}, 110 \mathrm{~V}, \mathrm{Xd}$ $=1.13 \mathrm{pu}, \mathrm{Xq}=1.03 \mathrm{pu}, X^{\prime} \mathrm{d}=0.12 \mathrm{pu}, X^{\prime \prime} \mathrm{d}$ $=0.1 \mathrm{pu}$.

2) Transformer parameters: $\Delta / Y$, $\mathrm{S}_{\max }=15 \mathrm{KVA}, 110 \mathrm{~V} / 440 \mathrm{kV}$

3) Transmission line: $440 \mathrm{kV}, Z=2.1+\mathrm{j} 2.7 \%$

4) Equivalent system: $440 \mathrm{kV}, \mathrm{Z}=1 \%$

\section{References}

[1] IEEE Power System Relaying Committee. "IEEE tutorial on the protection of synchronous generators." IEEE Power \& Energy Society, 2011.

[2] C. R. Mason, "A new loss-of-excitation relay for synchronous generators." Transactions of the American Institute of Electrical Engineers, 68 (2, pp.1240-1245, 1949.

[3] J.Berdy, "Loss of excitation protection for modern synchronous generators." IEEE Transactions on Power Apparatus and systems 94 (5) pp. 1457-1463, 1975.

[4] IEEE Power System Relaying Committee. "IEEE Guide for AC Generator Protection." IEEE Std. C 37 (2007), pp.1-177, 2007.

[5] Behnam Mahamedi, , Jian Guo Zhu, and Sayyed Mohammad Hashemi, "A setting-free approach to detecting loss of excitation in synchronous generators." IEEE Transactions on Power Delivery 31(5)pp. 2270-2278, 2015.

[6] Gazen, Yuri Neves, et al,"New setting of loss of excitation protection in $\mathrm{PQ}$ plan in order to maximize the operation area of the capacity curve of the synchronous machine", 2014 49th International Universities Power Engineering Conference (UPEC). IEEE, 2014.

[7] R. Sandoval, G.Armando, and J. A.Hector, "Dynamic simulations help improve generator protection." 2007 Power Systems Conference: Advanced Metering, Protection, Control, Communication, and Distributed Resources. IEEE, 2007.

[8] M. Ostojić, , and D. Milenko, "The algorithm for the detection of loss of excitation of synchronous generators based on a digitalphase comparator" Electrical Engineering 100 (2), pp.1287-1296, 2018.

[9] A. LM. Coelho, et al,"Loss-of-excitation protection and underexcitation controls correlation for synchronous generators in a real-time digital simulator", IEEE Transactions on Industry Applications 51(5), pp. 3579-3590, 2015.

[10] A. M. Sharaf and T. T. Lie, "ANN based pattern classification of synchronous generator stability and loss of excitation", IEEE transactions on energy conversion 9(4), pp.753-759, 1994.

[11] E. Pajuelo, , G.Ramakrishna, and S. S. Mohindar, "Identification of generator loss-ofexcitation from power-swing conditions using a fast pattern classification method", IET Generation, Transmission \& Distribution 7(1), pp. 24-36, 2013.

[12] S. R.Tambay, , and G. P.Yeshwant, "A new adaptive loss of excitation relay augmented by rate of change of reactance", IEEE Power Engineering Society General Meeting, 2005. IEEE, 2005.

[13] de Morais, Adriano P., Ghendy Cardoso, and L. Mariotto "An innovative loss-of-excitation protection based on the fuzzy inference mechanism." IEEE Transactions on Power Delivery 25 (4), pp. 2197-2204, 2010.

[14] B. Tianshu, et al. "Adaptive loss of field protection based on phasor measurements", 2011 IEEE Power and Energy Society General Meeting. IEEE, 2011.

[15] A. Mahdi, M. Davarpanah, and M. SanayePasand, "A novel approach to detect the synchronous generator loss of excitation", IEEE Transactions on Power Delivery 30 (3), pp. 1429-1438, 2014.

[16] J.Zhang, , et al. "Study on a new loss-of-field protection strategy", 2012 Asia-Pacific Power and Energy Engineering Conference. IEEE, 2012.

[17] T.Amraee,"Loss-of-field detection in synchronous generators using decision tree technique", IET Generation, Transmission \& Distribution 7(9), pp. 943-954, 2013).

[18] N.Noroozi, H. Yaghobi, and Y. AlinejadBeromi, "Analytical technique for synchronous generator loss-of-excitation protection", IET Generation, Transmission Distribution 11(9), pp. 2222-2231, 2017.

[19] M. S.Abdel Aziz, et al. "A novel study for hydro-generators loss of excitation faults detection using ANFIS", International Journal of Modelling and Simulation 37 (1), pp. 36-45, 2017.

[20] A. Moein, M. Sanaye-Pasand, and M. Davarpanah, "An analytical approach to detect generator loss of excitation based on internal voltage calculation", IEEE Transactions on Power Delivery 32(5), pp. 2329-2338, 2016

[21] A. Moein, et al. "A loss-of-field detection relay based on rotor signals estimation", IEEE Transactions on Power Delivery 33(2),pp. 779-788, 2017.

[22] H. Abbas, and F. Haghjoo, "A secure and setting-free technique to detect loss of field in synchronous generators", IEEE Transactions on Energy Conversion 32(4), pp.1512-1522; 2017.

[23] C. K., Seetharaman, S. P. Verma, and A. M. El-Serafi, "Operation of synchronous generators in the asynchronous mode"; IEEE Transactions on Power Apparatus and Systems, Vol.3 , pp. 928-939, 1974.

[24] A.Mati, and H.Bentarzi, "Enhanced positiveoffset mho element LOE protection of synchronous generator in the presence of STATCOM." Bul. Inst. Polit. laşi, Vol. 65 (69), Nr. 3, 2019.

[25] A. Mati, B.Bousaadia and H. Bentarzi, "A New Model of Numerical MHO Distance Relay Associated with Power Swing Detector", Algerian Journal of Signals and Systems, Vol.2, Issue 2, June 2017. 